\title{
Mudança estrutural e seu impacto na produtividade: uma análise da ascensão do setor de serviços na economia brasileira
}

\author{
Carolina Silvestri Cândido Rocha ${ }^{1}$ \\ Ana Lúcia Tatsch ${ }^{2}$ \\ Silvio Antônio Ferraz Cário ${ }^{3}$
}

\begin{abstract}
Resumo: Observa-se na realidade de diversos países, desenvolvidos e em desenvolvimento a ocorrência de mudança estrutural em direção à redução da participação da indústria no Produto Interno Bruto (BIP). Tal processo, denominado processo de desindustrialização, impacta a produtividade das economias de maneira diferente. Quando o setor de serviços emergente é capaz de ampliar a complexidade econômica, vê-se uma tendência de aumento de produtividade, no entanto, quando este não se relaciona diretamente ao setor industrial remanescente, ou seja, quando é composto por serviços não estratégicos, observam-se problemas no crescimento da produtividade. Nesse contexto, por meio da utilização de um modelo shift-share, baseado no modelo de decomposição canônica originário de Fabricant (1942), a realidade brasileira foi analisada visando caracterizar a direção da mudança estrutural e compreender sua consequência em termos de produtividade. Como resultado, verifica-se que o crescimento da participação do setor de serviços no emprego relaciona-sesobretudo com um aumento do emprego nos segmentos de serviços financeiros; seguros; serviços imobiliários e comerciais; e serviços comunitários, sociais e pessoais. Conclui-se que tal fenômeno decorre da ausência de dinamismo dos demais setores econômicos e não de medidas que proporcionam mudança estrutural para o aprofundamento da complexidade econômica e o aumento da produtividade.
\end{abstract}

Palavras-chave: Mudança estrutural, produtividade, desindustrialização, setor de serviços.

\section{Classificação JEL: L5o.}

Structural change and its impact on productivity: an analysis of the rise of the service sector in the Brazilian economy

\begin{abstract}
In many developed and developing countries, structural change is occurring in order to reduce the share of industry in GDP. This process, called the deindustrialization process, impacts the productivity of economies differently. When the emerging services sector is able to increase economic complexity, there is a tendency to increase productivity, however, when it is not directly related to the remaining industrial sector, that is, it is composed of non-strategic services, it is a problem to the productivity growth. In this context, through the use of a shift-share model based on the canonical decomposition model of Fabricant (1942), the Brazilian reality was analyzed in order to characterize the direction of the structural change and to understand its consequence in terms of productivity. As a result, growth in the share of the services sector in employment is mainly related to an increase in employment in the financial, insurance, real estate and commercial services, and community, social and personal services sectors. It is concluded that this phenomenon stems from the lack of dynamism of other economic sectors and not from measures that provide structural change to deepen economic complexity and increase productivity
\end{abstract}

1 Doutora em Economia com ênfase no Desenvolvimento pela Universidade Federal do Rio Grande do Sul (UFRGS), Universidade Tecnológica Federal do Paraná (UTFPR). E-mail: carolinasrocha@utfpr.edu.br

2 Ana Lúcia Tatsch é doutora em Economia pela Universidade Federal do Rio de Janeiro (UFRJ). Professora do Programa de Pós-Graduação em Economia da Universidade Federal do Rio Grande do Sul (UFRGS). E-mail: analuciatatsch@gmail.com

3 Silvio Antonio Ferraz Cario - Doutor em Economia pela Universidade Estadual de Campinas (UNICAMP) e Professor titular atuante nos Programas de Pós-Graduação em Economia e em Administração da Universidade Federal de Santa Catarina (UFSC).E-mail: fecario@yahoo.com.br 


\section{Introdução}

Observa-se que diversas economias têm vivenciado processos intensos de mudança estrutural, principalmente a partir da década de 1980. A indústria perde participação no PIB nas economias desenvolvidas, caracterizando um processo de desindustrialização. Nas economias emergentes, tal fenômeno também pode ser observado. No entanto, em função de essas economias não terem alcançado um nível elevado de industrialização e renda per capita, tal processo pode ser visto como um fenômeno precoce.

Nesse contexto, o presente artigo tem por objetivo analisar a relação entre mudança estrutural, principalmente a ascensão do setor de serviços, e a produtividade na economia brasileira.

O tema mudança estrutural e produtividade apresenta relevância no âmbito dos estudos referentes ao desenvolvimento econômico e produtivo. Dentre aqueles em que o Brasil é objeto de análise, cabe citar os que seguem. Rocha (2007), ao examinar a contribuição da mudança estrutural da indústria de transformação para o incremento da produtividade entre os anos de 1970 e 2001, conclui haver dubiedade na permanência de uma trajetória de crescimento de sua produtividade após a abertura econômica da década de 1990, já que os postos de trabalho foram criados em segmentos de menor crescimento da produtividade. Bonelli (2014) avalia se a chamada "armadilha da renda média" se aplica ao Brasil, isto é, se o lento crescimento está associado aos baixos níveis da produtividade à medida que se alcançam níveis médios de renda. Squeff e De Negri (2014), a partir de uma série de indicadores, negam a hipótese de que teria sido a redução da relevância da indústria na economia a responsável pelo baixo crescimento recente da produtividade do trabalho. Para esses autores, o que mais explica a evolução da produtividade no período recente é o fluxo de ocupações, particularmente da agropecuária para serviços. Jacinto e Ribeiro (2015) estudam a evolução da produtividade do setor de serviços entre 2002 e 2009, verificando uma evolução positiva em contraste com a queda na indústria. Já Santos e Spolador (2018) analisam a dinâmica da mudança estrutural na economia brasileira via modelo dinâmico de equilíbrio geral, avaliando a redução da participação do setor agropecuário no emprego e no valor adicionado e o aumento da participação do setor de serviços. Concluem, por meio de simulações, que os ganhos de produtividade no setor agropecuário são limitados pela sua participação na economia brasileira como um todo e pela transferência de empregos para o setor de serviços. As teses recém-defendidas de Torezani (2019) e de Lazzari (2019) somam-se a esse debate. O primeiro verifica que o baixo dinamismo econômico do país nas últimas décadas é fruto de uma rigidez estrutural que implica ausência das atividades econômicas e apresenta maior potencial para estimular o crescimento econômico. O segundo indica que o baixo dinamismo da produtividade interna nos anos 2000 esteve relacionado à regressividade dinâmica da estrutura produtiva brasileira no período.

O presente artigo soma-se a esse esforço de melhor compreender o comportamento da produtividade no Brasil. Nesse sentido, avança na análise da produtividade brasileira, examinando o processo de mudança estrutural a partir de um melhor entendimento do papel dos diferenciados segmentos do setor serviços nessa dinâmica. Contribui ainda ao examinar a realidade brasileira vis-à-vis os movimentos em outras importantes economias diante das mudanças mais recentes atinentes aos paradigmas tecnológicos.

Para tanto, utiliza-se um modelo shift-share, variação do modelo de decomposição canônica elaborado por Fabricant (1942), apresentado em Timmer, De Vries e De Vries (2014). O método shiftshare propicia a mensuração da contribuição para a variação da produtividade da realocação de trabalhadores entre os distintos setores da economia. Permite isolar diferentes movimentos intra e extras setoriais e, assim, compreender como a realocação de trabalhadores entre setores da economia afeta a produtividade. Essa realocação representa um dos elementos que compõem a mudança estrutural. 
Com relação à estrutura deste artigo, além da Introdução e das Considerações Finais, o texto organiza-se em quatro outras seções. Na segunda, apresenta-se um resumo de como a literatura aborda a relação entre dinâmicas setoriais e produtividade. Na terceira, explicam-se os procedimentos metodológicos adotados e descreve-se a base de dados utilizada. Na quarta, são examinados os movimentos mundiais relativos à produtividade e, na quinta, analisadas a mudança estrutural e a produtividade no caso do Brasil.

\section{Articulação entre indústria, serviços e a produtividade}

A relação entre as dinâmicas setoriais e a produtividade é amplamente abordada na literatura econômica. Os setores que compõem a economia apresentam características particulares que os distinguem. A indústria coloca-se como um setor particularmente capaz de elevar a produtividade das economias, uma vez que é intensivo em capital, o que permite que se amplie o valor agregado por trabalhador. No tocante ao setor de serviços, este caracteriza-se, particularmente, pelo uso intensivo de mão de obra,pela simultaneidade de produção e consumo e por produtos intangíveis, pouco padronizáveis e não estocáveis (AMBROZIO; MELO, 2017).

O aumento recente da participação do setor de serviços nas economias fomentou o debate sobre como esse fenômeno afetaria a evolução da produtividade. Segundo Jacinto e Ribeiro (2015), a produtividade da indústria passou a ser associada ao desempenho do setor de serviços, pois se observa uma crescente participação deste no PIB.

A exemplo disso, Baumol (1967), Baumol et al. (1985), Rodrik (2011, 2014), Busso et al. (2013), Malo et al. (1998), Castellacci (2007)estudam a relação entre o setor de serviços e a produtividade. Inicialmente, tinha-se a compreensão de que o aumento da participação do setor de serviços no PIB promoveria uma estagnação na produtividade, haja vista seu parco desenvolvimento produtivo, observado como um setor residual. Essa abordagem é conhecida como doença dos custos dos serviços.

A observância do setor de serviços como residual e redutor da produtividade passa a ser contestada devido a dois aspectos. Primeiramente, em função da alta heterogeneidade do setor de serviços, que abarca tanto segmentos que absorvem mão de obra de baixa qualificação quanto outros como o segmento dos serviços de informação e software, nos quais a inovação é permanente. Segundo, dada a sua elevada capacidade de avançar diante das alterações nos ambientes competitivos. Como nesse setor se observa menor necessidade de imobilização de capital, muitas alterações paradigmáticas da economia o impactam rapidamente e promovem mudanças que depois se estendem aos demais (SILVA, 2006; PEREIRA et al, 2013).

Nesses termos, pode-se separar, grosso modo, o setor de serviços em segmentos tradicionais, em que a inovação é menos presente e mais resistente à mudança, mas impacta o emprego e a geração de renda devido ao seu tamanho; e em segmentos dinâmicos, nos quais a inovação é permanente e, portanto, com maior potencial de evolução e crescimento da produtividade (SILVA, 2006; PEREIRA et al., 2013).

No tocante à realidade brasileira, os estudos realizados acerca da produtividade e do setor de serviços têm como foco a relação deste com a indústria (JACINTO; RIBEIRO, 2015). Muitos buscam comprovar a existência da doença de custos na economia nacional. Melo et al. (1998) apontam não encontrar evidências que ratifiquem a ocorrência desse fenômeno para as décadas de 1980 e 1990. Oliveira (2011) assinala haver evidências de que o setor de serviços contribuiu para o crescimento da produtividade agregada após 1994 e que, assim sendo, não se constata a ocorrência de doença de custos no Brasil até meados dos anos 2000.

Ainda no que se refere à realidade desse setor no país, vê-se que os serviços empresariais intensivos em conhecimento corroboram a inovação. Há concentração espacial importante no setor de serviços. Empresas de capital estrangeiro são, em geral, mais produtivas do que as de capital nacional. Da mesma forma que na indústria, variáveis relacionadas à escala, à tecnologia, à dotação de fatores contribuem para diferenciar empresas exportadoras e não exportadoras (SILVA, 2006).

Observa-se que a produtividade do setor de serviços brasileiro é baixa, oscilante e heterogênea. $\mathrm{O}$ nível reduzido sugere que o setor opera com baixo nível de capital e tecnologia e que desenvolve pouca 
inovação. As oscilações podem decorrer de alterações nos preços relativos dos serviços e também de dificuldades e erros de medida. A heterogeneidade deriva dessa característica própria do setor. Diferentemente de outros setores, as empresas menores tendem a ser mais produtivas, o que pode estar associado a fatores institucionais e à natureza menos favorável a ganhos de escala desse setor. Os indicadores associados ao capital humano e à integração econômica internacional estão entre as variáveis que mais condicionam a produtividade em serviços (ARBACHE, 2015).

A elevada participação do setor de serviços na economia nacional, assim como sua elevada presença na matriz de custos de outras atividades econômicas, ratifica a importância que o aumento da produtividade dos serviços tem para a economia nacional como um todo. A visão tradicional de que o setor de serviços apresenta baixos índices de produtividade e inovação per si é inadequada. O setor de serviços é extremamente heterogêneo e, assim, há segmentos mais dinâmicos que outros. Os serviços são insumos fundamentais para qualquer economia moderna e têm papel importante na difusão de inovações e de ganhos de produtividade para outros setores. Assim, diante das características econômicas atuais, o desenvolvimento passa pela consideração do setor de serviços como peça-chave para a produtividade (ARBACHE, 2015; SILVA, 2006).

\section{Procedimentos metodológicos: base de dados e modelo proposto}

No tocante ao modelo shift-share calculado, utilizou-se o banco de dados de nível de produtividade da Groningen Growth and Development Center (GGDC), que apresenta dados sobre preços relativos e produtividade da mão de obra para 42 grandes economias e até 35 setores industriais. Tal banco considera as informações do World Input-Output Database (WIOD). Os dados disponibilizados são baseados nos resultados do Programa de Comparações Internacionais de 2005 (ICP), que estima as paridades de poder de compra (PPPs) para uma amostra global de países (GGDC, 2015).

A base de dados foi desenvolvida pela Faculdade de Economia e Negócios da Universidade de Groningen, instituição holandesa. Estudos comparativos de crescimento têm sido dificultados pela falta de um sistema internacional de dados sobre produção e tendências de produtividade por setor, principalmente e países em desenvolvimento. Esse banco de dados apresenta-se como o primeiro com séries de longo prazo referentes ao desenvolvimento setorial dos países (GGDC, 2015). Ele foi construído com base em um estudo aprofundado de fontes estatísticas disponíveis de cada país considerado. Nos procedimentos metodológicos disponibilizados pela universidade, encontra-se o detalhamento sobre o conteúdo da base de dados, o procedimento de seleção das fontes utilizadas, as principais fontes de dados e procedimentos de vinculação, bem como os métodos empregados para garantir a intertemporalidade (consistência intertemporal), a consistência interna e a conformidade (consistência internacional), visando garantir a utilidade do banco de dados em análises de longo prazo (GGDC, 2015).

O conjunto de dados que compõe o banco atualmente inclui dados anuais, a partir de 1950, sobre o valor adicionado bruto (VA) e o pessoal ocupado (PO) a preços correntes inconstantes de 2005 para onze países asiáticos, nove latino-americanos, dois do Oriente Médio, doze africanos, Estados Unidos e conjunto de países europeus. Relacionados, os dados de VA e PO permitem a derivação de tendências de produtividade do trabalho ${ }^{4}$ (valor agregado por trabalhador).

4A produtividade, conceituada como o grau de eficiência com que determinada economia utiliza seus recursos, é mensurada por meio da produtividade do trabalho, em detrimento da Produtividade Total dos Fatores (PTF). Enquanto a produtividade do trabalho é um indicador mais apropriado para identificar o padrão de subsistência dos trabalhadores e comparar padrões ao longo de diferentes economias, a PTF pretende indicar a eficiência com que a economia combina seus recursos para gerar produto.

A produtividade do trabalho é um indicador de fácil mensuração e sua utilização tem como principal benefício a maior disponibilidade de dados em diversos cortes analíticos, permitindo a comparabilidade de realidades econômicas distintas. Em contrapartida, a interpretação de sua dinâmica apresenta-se problemática, uma vez que há vários determinantes que influenciam seu comportamento, o que dificulta a identificação das causas por trás de suas variações no tempo. A PTF é um indicador mais complexo que busca separar os efeitos na produtividade de fatores produtivos, como capital e trabalho e atribuem os ganhos de produto, não oriundos a esses fatores, ao resultado do progresso técnico. Porém esse indicador é de difícil mensuração, pois requer a identificação de todos os recursos da economia, a mensuração de cada um destes e a 
A base equaliza as metodologias visando uniformização de dados e, assim, permite estudos comparativos entre países. $\mathrm{O}$ banco de dados abrange os dez principais setores da economia, tal como definidos na norma internacional Classificação, Revisão 3.1 (ISIC rev. 3.1). Esses dez setores cobrem o total da economia (GGDC, 2015). Para o caso brasileiro, a base reúne dados de fontes como IBGE, CEPALSTAT, World Input-Output Database (WIOD) Socio Economic Accounts, conforme Quadro 1. Para todos os países, são utilizadas metodologias de testes que garantem a consistência da base de dados. A última atualização disponível é de julho de 2013 (GGDC, 2015).

Quadro 1: Base de dados por variável e ano utilizados

\begin{tabular}{|l|l|}
\hline \multicolumn{2}{|l|}{ Valor adicionado (VA) por setor a preços constantes de 2005} \\
\hline $1950-1990$ & Taxa de crescimento setorial apresentada por Mulder (1998) \\
\hline $1991-1994$ & Taxa de crescimento setorial coletada nas Contas Nacionais (IBGE) \\
\hline $1995-2009$ & WIOD - contas socioeconômicas, release de fevereiro de 2012 \\
\hline $2009-2012$ & Tendências setoriais da CEPALSTAT \\
\hline Pessoal ocupado (PO) por setor \\
\hline $1950-1989$ & Taxa de crescimento setorial apresentada por Mulder (1996) \\
\hline $1991-1994$ & Taxa de crescimento setorial coletada nas Contas Nacionais (IBGE) \\
\hline $1995-2009$ & WIOD - contas socioeconômicas, release de fevereiro de 2012 \\
\hline $2009-2012$ & Tendências setoriais da CEPALSTAT \\
\hline
\end{tabular}
Fonte: elaboração própria a partir de GGDC (2015)

A base apresenta a seguinte divisão setorial: agricultura, caça, silvicultura e pesca (A e B); mineração e pedreiras $(C)$; transformação $(\mathrm{D})$; eletricidade, gás e abastecimento de água (E); construção (F); comércio, hotéis e restaurantes $(\mathrm{G}$ e H); transporte, armazenamento e comunicação (I); finanças, seguros, serviços imobiliários e comerciais ( $\mathrm{J}$ e $\mathrm{K}$ ); serviços governamentais ( $\mathrm{L}$ e $\mathrm{N}$ ); serviços comunitários, sociais e pessoais (O e P) do código ISIC revisão 3.1. A produtividade setorial é calculada pela divisão do valor adicionado a preços constantes de 2005, em dólares, pelo pessoal ocupado setorial.

O modelo utilizado no presente artigo é uma variação do modelo de decomposição canônica apresentado por Fabricant (1942) e reformulado em Timmer, De Vries e De Vries (2014). Autores como McMillan e Rodrik (2011), Rodrik (2013), Timmer e Szirmai (200o), e Marconi e Aragão (2016) também apresentaram estudos baseados no modelo de Fabricant (1942).

O modelo apresentado por Timmer, De Vries e De Vries (2014) permite compreender os efeitos da realocação do emprego na produtividade, evidenciando se a variação da produtividade decorreu da variação da produtividade setorial, do deslocamento do emprego para setores de níveis distintos de produtividade ou onde se observa variação na taxa de crescimento desta.

Primeiramente calculou-se a participação dos distintos setores, termo Si,no pessoal ocupado da economia, em que o subscrito i representa cada setor. Assim, $\mathrm{Si}=\mathrm{POi} / \mathrm{PO}$ em que PO é o pessoal ocupado. Em seguida, por meio do quociente entre valor adicionado (VA) e emprego, calculou-se o nível de produtividade do trabalho, $\mathrm{Pi}$, também de cada setor ida economia. $\mathrm{O}$ nível de produtividade foi calculado com base no quociente entre produtividade setorial e produtividade total. O sobrescrito o refere-se ao período inicial e o subscrito $\mathrm{T}$ ao final, sendo assim a diferença entre $\mathrm{T}$ e $\mathrm{o}$ a variação temporal de cada variável.

O método pode ser expresso pela Equação (1):

$$
\Delta P=\sum_{i}\left(P_{i}^{T}-P_{i}^{0}\right) S_{i}^{0}+\sum_{i}\left(S_{i}^{T}-S_{i}^{0}\right) P_{i}^{0}+\sum_{i}\left(P_{i}^{T}-P_{i}^{0}\right) x\left(S_{i}^{T}-S_{i}^{0}\right)
$$

Os movimentos descritos estão sintetizados em três efeitos: "within-effect", efeito de realocação estático e efeito de realocação dinâmico. O primeiro somatório diz respeito ao "within-effect". Neste,

determinação de como se combinam, e qual sua dotação para a geração do produto. Sua qualidade é promover um diagnóstico mais preciso dos determinantes da produtividade. Como no presente artigo se busca promover uma comparação ampla da produtividade, a utilização da produtividade do trabalho faz-se mais adequada, principalmente diante da disponibilidade de dados. 
fez-se o somatório da variação da produtividade dos setores entre o período $\mathrm{T}$ e o, ponderada pela participação de cada setor i no emprego da economia. Esse efeito capta a variação da produtividade setorial. Caso não haja realocação setorial do emprego, a produtividade pode variar decorrente de alterações produtivas intrassetoriais. $\mathrm{O}$ segundo, o efeito de realocação estático, é calculado com base no somatório da variação da participação setorial no emprego total entre os períodos T e o, multiplicada pelo nível relativo de produtividade setorial do período o. Com este, capta-se a variação da produtividade decorrente da realocação setorial do emprego, independente da variação da produtividade, ou seja, se setores mais produtivos aumentarem sua participação no emprego na economia estudada, a variação da produtividade será positiva. O terceiro, o efeito de realocação dinâmico, calcula-se com base no somatório da multiplicação da variação setorial da produtividade e da participação do emprego entre os períodos $\mathrm{T}$ e o. Para este, a variação da produtividade decorre da realocação do emprego em setores onde a produtividade também varia.

Os períodos de dados selecionados, 1960-1975 (boom econômico mundial), 1975-1990 (mudança radical nos prospectos econômicos para as economias em desenvolvimento) e 1990-2010 (período de desenvolvimento e auge do paradigma nas Tecnologias de Informação e Comunicação - TICs) são utilizados visando compreender a influência de mudanças estruturais apontadas na literatura econômica na ascensão do setor de serviços e, assim, na produtividade.

É importante ressaltar que essa metodologia permite compreender os efeitos da realocação setorial do emprego na produtividade, fundamental para compreender as características do processo observado de crescimento da participação do setor de serviços na economia. Do resultado obtido, pode-se sugerir e avalizar, com o aporte de dados adicionais, a natureza do processo descrito.

\section{Mudança estrutural e produtividade: cenário mundial}

Pelas diversas formas analisadas - razão entre o Valor Adicionado (VA) e o número de trabalhadores, PIB por trabalhadores, Produtividade Total dos Fatores (PTF) -, a conclusão, diante dos movimentos mundiais da produtividade, é a mesma. Isto é, a produtividade tem mostrado tímido crescimento, o que já pode ser observado até mesmo antes da crise financeira global.

A produtividade mundial acompanhou o baixo crescimento registrado no PIB em anos recentes. $\mathrm{O}$ crescimento da produtividade mundial, de 2013 a 2014, foi de apenas 2,1\%, insuficiente para recuperar o valor registrado em momento anterior à crise, de 2,6\% em média ao ano (de 1999 a 2006). A estagnação na produtividade global foi resultado de poucas mudanças nas taxas de crescimento do produto e do emprego e, em anos recentes, 2016, 2017 e 2018, observou-se pequeno avanço - a produtividade do trabalho cresceu $1 \%, 4 \%, 2 \%$ e 1,9\%, respectivamente. O crescimento médio anual da produtividade de $2,9 \%$, entre 2000 a 2007 , reduziu-se para $2,3 \%$ entre os anos 2010 e 2017 , evidenciando que os efeitos da transformação digital observada ainda são muito pequenos para refletir em avanços significativos na macroeconomia dos países (THE CONFERENCE BOARD, 2019).

O insignificante avanço da produtividade decorre de diversos fatores: da redução no crescimento da produtividade dos Estados Unidos e do Japão, da desaceleração no crescimento da produtividade chinesa, da estagnação na produtividade latino-americana e da redução no crescimento da produtividade russa. Apenas na Índia e na África Subsaariana houve registro de aumento das taxas de crescimento, insuficientes para compensar o fraco desempenho dos outros países (THE CONFERENCE BOARD, 2017).

A redução das taxas de crescimento das economias maduras é um fenômeno de longo prazo, que se inicia antes da crise financeira e econômica de 2008-2009. Desde 2005, as taxas de crescimento da produtividade decrescem nos Estados Unidos, quando as inovações proporcionadas pela utilização das Tecnologias de Informação e Comunicação (TICs) foram absorvidas. Na Europa e no Japão, a tendência de crescimento da produtividade inferior àquela registrada nos Estados Unidos se inicia nos anos 1990 e está relacionada a um ritmo mais vagaroso de adaptação e inovação tecnológica, especialmente no setor de serviços (THE CONFERENCE BOARD, 2017).

A relação entre a queda no crescimento da produtividade global e os movimentos de rápida mudança tecnológica e inovação, especialmente da fase recente das TICs, é contraditória. 
Historicamente, tais mudanças deveriam promover elevação na produtividade; assim, observa-se que a fraqueza no crescimento da produtividade nos últimos anos reflete a lentidão pela qual as novas tecnologias se traduziram em produtividade (DABLA-NORRIS et al., 2015; THE CONFERENCE BOARD, 2015).

A crise econômica e financeira global tem influência nisso, pois provocou redução na demanda, causando baixo investimento. A flexibilização monetária (quantitative easing) levou a retornos baixos nos investimentos da economia real. As baixas taxas de juros têm pouco efeito na aceleração do investimento. $\mathrm{O}$ baixo custo do capital pode ter deixado as empresas menos produtivas nos negócios e mudado os incentivos para que mantivessem caixa, bem como influenciou a alocação dos recursos dos investidores em instrumentos financeiros e imóveis, em vez de em investimentos produtivos que originassem oportunidades de crescimento e inovação (DABLA-NORRIS et al., 2015).

A queda no crescimento do capital humano e físico por trabalhador, desde a década de 1990, também contribuiu para o declínio da produtividade nas economias maduras ${ }^{5}$. $\mathrm{O}$ aprofundamento do capital das TICs, amplamente considerado como uma vantagem competitiva norte-americana na produtividade do trabalho sobre as economias europeias recuou do pico alcançado em meados da década de 1990. O declínio no aprofundamento do capital nas TICs em muitas economias avançadas também antecedeu a crise, refletindo em parte uma diminuição de longo prazo do investimento público. O nível de escolaridade também está próximo da estabilização na maioria das economias avançadas. Para as gerações nascidas depois de 1950, nos Estados Unidos, o aumento da escolaridade cessou (DABLA-NORRIS et al., 2015).

As economias em desenvolvimento ${ }^{6}$ registraram evolução no crescimento da produtividade do trabalho de 2014 (3,4\%), comparando-se à de 2013 (3,3\%). O crescimento da produtividade dos mercados emergentes é inferior ao que foi registrado no início dos anos 200o, quando a média figura entre $5 \%$ e $7 \%$. Nos anos recentes, 2016 e 2017, a produtividade cresceu $2,2 \%$ e 2,8\%, respectivamente. Porém, há diferença registrada entre as economias emergentes (THE CONFERENCE BOARD, 2017).

A produtividade chinesa registra taxas de crescimento decrescentes ao longo dos anos - de2007 a 2012, a média foi de 9,5\%, em comparação a 7,3\% em 2013, e a 7\% em 2014. Na Î́ndia, o crescimento da produtividade de 2,8\% em 2013 foi superado em 2014, quando atingiu 3,8\%, apesar da desaceleração em 2016; esse país se destaca com uma das maiores taxas de crescimento da produtividade. Em contrapartida, a produtividade brasileira, que cresceu 1,8\% em 2013, registrou crescimento de apenas $0,3 \%$ em 2014, e decréscimo em 2015, 2016 e 2017. A produtividade mexicana apresentou pequeno aumento da taxa de crescimento, passando de o,5\% em 2013 para o,6\% em 2014, e a produtividade russa também reduziu seu crescimento: o,4\% em 2014 em comparação a 1,5\% em 2013 (THE CONFERENCE BOARD, 2017).

A produtividade e a dinâmica setorial estão intimamente atreladas e as alterações setoriais recentes fornecem informações sobre o comportamento da produtividade. No tocante à mudança estrutural, a realocação de fatores produtivos entre setores pode promover elevação na produtividade quando ocorre em direção a setores de maior competitividade e eficiência.

Diferentes aspectos explicam esse processo nas economias avançadas e em desenvolvimento. Tomese a globalização, por exemplo. Em muitas economias avançadas, esse processo foi acompanhado pela terceirização de algumas atividades de alta produtividade para as economias emergentes. As mudanças tecnológicas, como a revolução das TICs e a mudança para produção mais intensiva em conhecimento, tiveram profundas implicações para as estruturas de produção.

Ao longo das últimas quatro décadas, as economias avançadas experimentaram mudanças em sua estrutura em benefício do setor de serviços, havendo um processo de desindustrialização natural. As economias em desenvolvimento também apresentam tal tendência, mas de forma precoce, uma vez que não atingiram o mesmo padrão de renda per capita das economias avançadas (TIMMER; DE VRIES; DE VRIES, 2014).

\footnotetext{
${ }^{5}$ Estados Unidos, União Europeia, Japão, Austrália, Canadá, Islândia, Israel, Hong Kong, Noruega, Coreia do Sul, Suíça, Nova Zelândia, Singapura e Taiwan.

${ }^{6}$ Inclui as demais economias, exceto as economias maduras
} 
No Gráfico 1, tem-se a participação da indústria e do setor de serviços no PIB dos países que compõem a Organização para a Cooperação e Desenvolvimento Econômico ( $\mathrm{OCDE}^{7}$ ) a América Latina e do mundo. A participação referente ao setor de serviços corresponde ao eixo primário - à esquerda -, e aquela referente ao setor industrial está localizada no eixo à direita. É possível observar que, além da participação média mais elevada do setor de serviços, este também apresenta tendência ascendente, ao passo que a indústria perde participação, o que ratifica o processo de desindustrialização tanto nas economias desenvolvidas quanto nas subdesenvolvidas.

Gráfico 1: Participação da indústria e serviços no PIB dos países da OCDE, América Latina e mundo - 1997 a $2015($ em \%)

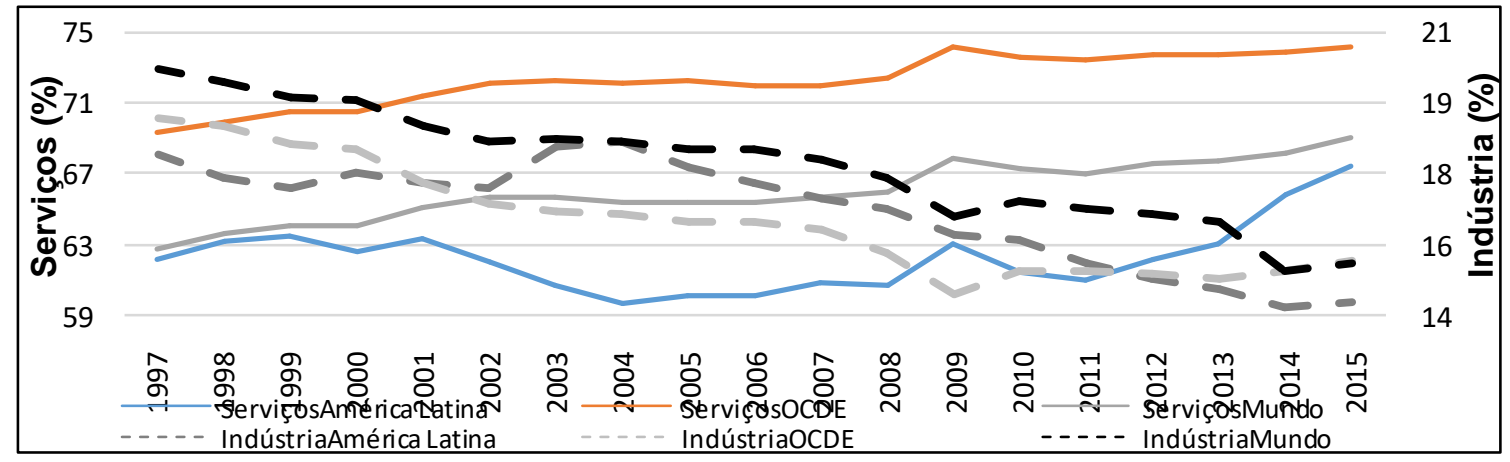

Fonte: Dados do Banco Mundial (2017).

Diante do processo de desindustrialização observado nas economias, assim como da diferença deste nas economias em fases distintas de desenvolvimento, o setor de serviços,assim como seu comportamento simbiótico com a indústria, tem se tornado tema relevante de análise. A produtividade e a mudança estrutural dependem mais de alterações em direção ao aumento da complexidade das estruturas produtivas do que da participação da indústria nas economias.

Nesse contexto, importa ressaltar que o setor de serviços capaz de promover aprofundamento da complexidade econômica surge após a consolidação de um setor industrial robusto. Completar o processo de industrialização é condição necessária para que o processo de desindustrialização, que ocorre naturalmente nas economias desenvolvidas, preserve a complexidade econômica.

Observa-se nas economias subdesenvolvidas que o processo precoce de desindustrialização faz emergir da estrutura econômica um setor de serviços de menor qualificação, incapaz de promover aprofundamento da complexidade econômica. Pode-se afirmar que muito do crescimento observado no setor de serviços decorre de políticas econômicas de incentivo à demanda.

O setor de serviços apresenta a peculiaridade de estar relacionado aos demais que compõem a estrutura produtiva dos países, e, entre eles, é o mais diversificado. Desse modo, uma economia com uma indústria robusta requer uma série de serviços de apoio - normalmente intensivos em conhecimentos, estratégicos, que proporcionam agregação de valor ao complexo industrial. Uma economia em que não se observa essa relação, no geral, sustentará serviços de baixas qualificação, complexidade e produtividade, voltados às famílias.

Quando se abordam temas como regimes tecnológicos, trajetórias e produtividade em uma lógica interssetorial, a indústria apresenta papel preponderante, pois representa a engrenagem do crescimento e a parte mais inovadora dos sistemas econômicos. Porém, em anos recentes, é possível verificar nessa dinâmica uma alteração que coloca o setor de serviços como parte importante do sistema, visto que tem experimentado rápido crescimento e é responsável pela maior parte do valor adicionado e do emprego nos países industrializados (CASTELLACCI, 2007).

\footnotetext{
${ }^{7}$ Irlanda, Estônia, Áustria, Austrália, Bélgica, Islândia, Polônia, Dinamarca, Alemanha, França, Finlândia, Coreia do Sul, Luxemburgo, Canadá, República Tcheca, Países Baixos, Estados Unidos, México, Noruega, Reino Unido, Chile, Portugal, Japão, Suécia, Suíça, Eslováquia, Eslovênia, Turquia, Espanha, Grécia, Nova Zelândia, Hungria, Israel, Itália e Letônia.
} 
No Gráfico 2, apresentam-se os dados referentes à produtividade do trabalho e à participação setorial para o ano de 2010. A produtividade setorial apresentada é relativa à produtividade total o que permite desconsiderar as idiossincrasias nacionais. Os países selecionados visam permitir a comparação de realidades distintas de desenvolvimento e produtiva ${ }^{8}$. $\mathrm{O}$ objetivo deste é ratificar a importância da indústria nas economias por ser um setor de produtividade elevada e de participação representativa no emprego. A combinação dos dois elementos, produtividade e representatividade na participação do emprego, é o que caracteriza a indústria como um setor de relevância nas economias.

Em todos os países, a mineração destacou-se como o setor mais produtivo, o que decorre de sua intensidade em capital. Porém a mineração apresenta pífia representatividade em termos de emprego nas economias, com participação de $0 \%$, lê-se inferior a $1 \%$, representada dessa forma em decorrência de arredondamento. Os efeitos positivos decorrentes da alta produtividade são anulados pela baixa representatividade em termos de emprego desse setor nas economias.

Em seguida, o destaque é o setor industrial (indústria de transformação), que, exceto na China, apresenta-se como o segundo setor mais produtivo em todos os países. A importância da indústria como setor econômico é ratificada ao se observar a participação desse setor no emprego total dos países selecionados. A indústria de transformação é, na maioria das economias (exceto na China), o setor que apresenta a segunda maior parcela de emprego, atrás apenas do setor de serviços, e a segunda maior produtividade. Combinando sua elevada participação no emprego (em torno de $20 \%$ ) com as suas características em termos de produtividade, tem-se a importância desse setor na estrutura produtiva. Apesar de elevada participação no emprego, o setor de serviços apresenta produtividade inferior à da indústria. A agricultura apresenta baixa participação no emprego e baixa produtividade na maioria dos países, exceto na China, onde a participação no emprego é elevada.

Gráfico 2: Produtividade setorial de países selecionados

(VA a US\$ constantes de 2010/emprego - produtividade total do país $=100$ ) -2010

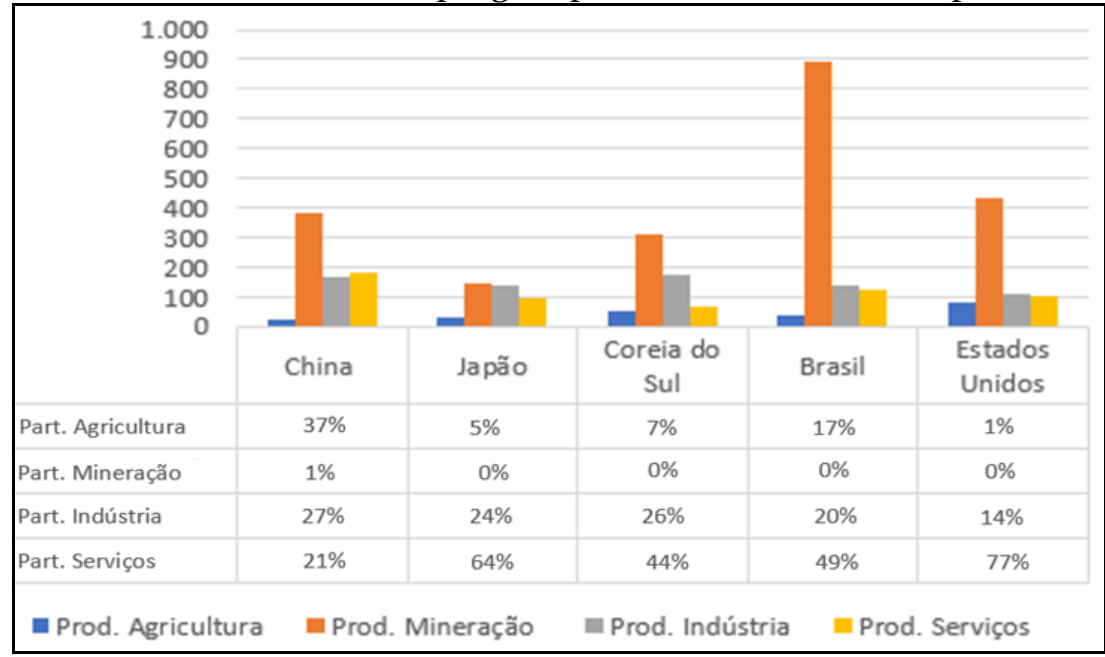

Fonte: Dados do GGDC (2017).

Tradicionalmente, explica-se a emergência do setor de serviços por conta de seus menores níveis de produtividade e dinâmica mais lenta em relação à indústria de transformação. No entanto essa visão tradicional dos serviços, como desvios de produtividade e absorvedores de emprego, tem sido questionada pelo grande dinamismo que alguns segmentos de serviços avançados mostram em relação ao surgimento e a difusão de TICs (CASTELLACCI, 2007).

Recentemente, um novo conjunto de inovações radicais inter-relacionadas tem sido progressivamente introduzido no sistema econômico, primeiro na indústria de semicondutores e, mais tarde, nos setores de software e de telecomunicações. Eles começam a se difundir mais rapidamente a partir do início dos anos 1990. Como parte da difusão das novas tecnologias, um conjunto relacionado

\footnotetext{
${ }^{8}$ Os dados para a Alemanha não estão disponíveis nessa mesma metodologia.
} 
de inovações se espalhou, baseado na multimídia e na Internet, ligado às atividades de publicação e entretenimento, e a toda uma gama de novos serviços (redes de voz, cabo, celular e comunicações por satélite, transmissão de dados, redes etc.). O crescimento dos serviços avançados está, portanto, relacionado ao surgimento de um novo paradigma tecnológico caracterizado pela penetração e pelo potencial de crescimento trazido pelas TICs (CASTELLACCI, 2007; FREEMAN; LOUÇÃ, 2001).

O avanço observado nesses serviços define um padrão de terceirização que pode ser explicado pelas diferentes atribuições das atividades existentes, e não por um processo real de mudança e criação estrutural de serviços inteiramente novos, e que está inerentemente relacionado à crescente complexidade do processo produtivo baseado no conhecimento. Portanto, constitui um aspecto importante da maior especialização tecnológica e econômica que caracteriza a produção moderna (FIXLER; SIEGEL, 1999).

A terceirização reflete um intenso processo de mudança estrutural e uma reorganização radical da divisão do trabalho entre setores tecnologicamente avançados. Logo, esse processo está levando a uma interdependência crescente entre ambos os setores (indústria e serviços intensivos em conhecimento) e a um intercâmbio de conhecimento mais intenso entre as atividades da indústria e de serviços. Um fator crucial de vantagem competitiva no novo paradigma tecnológico baseado em TICs é representado pela interdependência e por vínculos verticais, que unem diferentes grupos de setores de manufatura e serviços (ANTONELLI, 1998; DI CAGNO; GUERRIERI; MELICIANI, 2005; MELICIANI, 2005; WINDRUM; TOMLINSON, 1999;).

Nesse contexto, comprova-se quea produtividade do trabalho das indústrias relacionadas às novas tecnologias de propósitos gerais, principalmente aquelas relacionadas às TICs aumentaram progressivamente sua contribuição para o crescimento da economia, enquanto a relacionada ao núcleo industrial fordista apresentou uma tendência à estagnação ou decréscimo (CASTELLACCI, 2007).

Os grupos tecnologicamente mais avançados vêm aumentando significativamente sua contribuição para a produtividade agregada do trabalho desde o início dos anos 1980. Seu nível de produtividade está muito acima da média da economia. Já os últimos (grupos tecnicamente menos dinâmicos) são caracterizados por tendências estáveis ou decrescentes da produtividade (CASTELLACCI, 2007).

Gráfico 3: Produtividade do trabalho dos Estados Unidos, do Brasil e da Alemanha (US\$ de 2016, PPP) e 2011) - 1960 a 2016

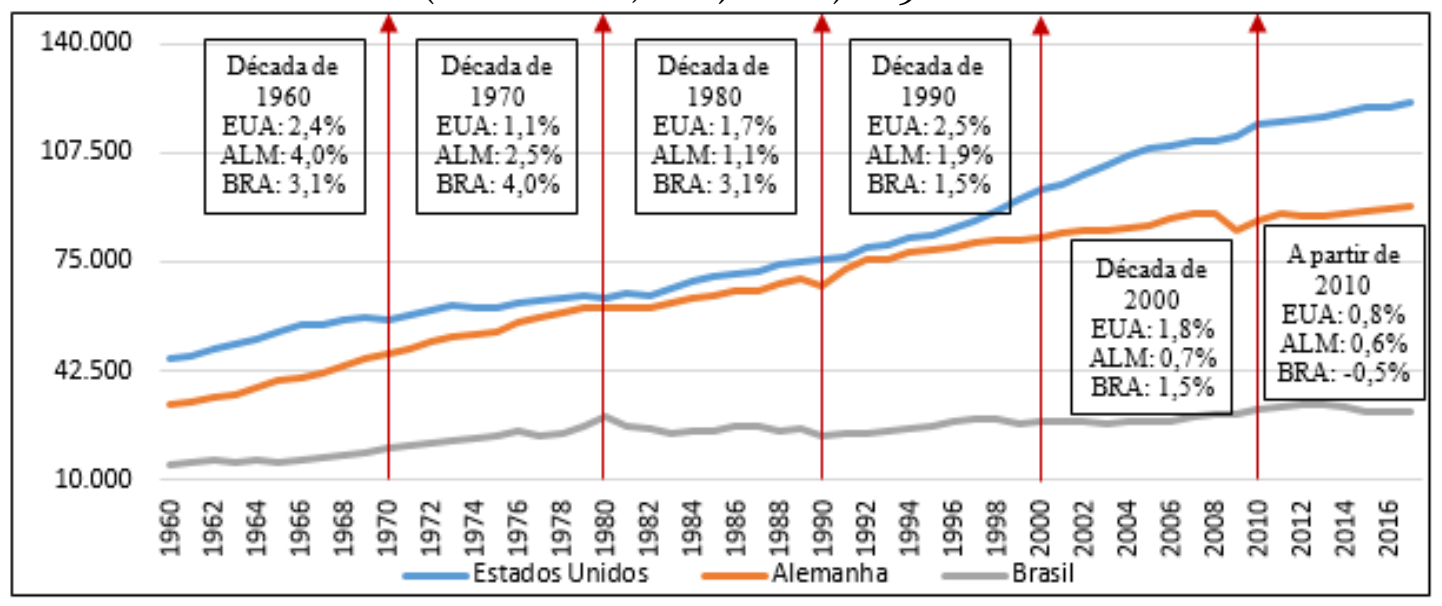

Fonte: The Conference Board (2017).

No Gráfico 3, verifica-se como evoluiu a produtividade do trabalho nos Estados Unidos (EUA), na Alemanha (ALM) e no Brasil (BRA). A escolha dos países deu-se em razão de ilustrarem o apresentado até então. Os Estados Unidos figuram como país de destaque no que se refere às TICs, comparado à realidade europeia - representada pela Alemanha -, já o Brasil é o país central de análise. Destaca-se que a produtividade brasileira apresentou, nas décadas de 1960 e 1970, a maior variação média. Nessas décadas, o país passava por um processo de industrialização pesada. Em seguida, vale sublinhar a elevação da produtividade norte-americana na década de 1990, ratificando o efeito explanado acerca das 
TICs. Ainda no que tange a esse tema, aponta-se a redução das taxas de crescimento da produtividade brasileira, principalmente da década de 1990 até a atual, o que evidencia que o efeito observado nos Estados Unidos e, em menor proporção, na Alemanha, não ocorreu no Brasil.

O setor de TICs imprimiu amplo efeito na produtividade agregada através de seu papel de promotor de inovações complementares, incluindo a reorganização de negócios em outros serviços. $O$ crescimento médio da produtividade de bens e serviços relacionados às TICs liderou todos os setores durante o período 2000-2007, particularmente nos Estados Unidos e nos países nórdicos. Em contrapartida, o Japão, a Europa central e os países da área do euro com alto endividamento demoraram a se modernizar nesse quesito (DABLA-NORRIS et al., 2015).

Em síntese, o cenário mundial acerca da produtividade é de estagnação. Por vezes, atribui-se esse comportamento aos processos de desindustrialização, o que promove redução da indústria - setor de alta produtividade - em benefício do aumento da participação do setor de serviços - setor de produtividade inferior - nas economias. Porém verifica-se que esse processo é dúbio, ele depende da conformação da estrutura produtiva previamente ao seu acontecimento.

Nas economias desenvolvidas avançadas, a terceirização de atividades da indústria para o setor de serviços decorre do aprofundamento do paradigma tecnológico fundamentado nas TICs. Este se inicia após a consolidação de um setor industrial robusto. Nas economias em desenvolvimento, observa-se que o processo de desindustrialização se inicia antes de se alcançar a consolidação do setor industrial, o que dá origem a um setor de serviços desintegrado aos demais setores produtivos e afastado da fronteira tecnológica.

\section{Mudança estrutural e a produtividade: o caso do Brasil}

Perante a lógica atual de mudança estrutural observada nas economias desenvolvidas, a realidade setorial brasileira é analisada na presente seção, visando identificar o que explica a estagnação da produtividade do país. No Gráfico 4, observa-se a evolução da produtividade brasileira de 1950 a 2011. No eixo primário, apresentam-se os setores da economia, exceto a mineração, e a produtividade total em milhões de dólares por trabalhador (valores de 2005). No eixo secundário, a mineração. A escolha por colocar a mineração em um eixo secundário decorre da elevação recente da produtividade desse setor, que ofusca a análise dos demais setores.

Gráfico 4: Produtividade total e setorial brasileira (milhões de US\$ de 2005 por pessoal ocupado) - 1950 a 2011

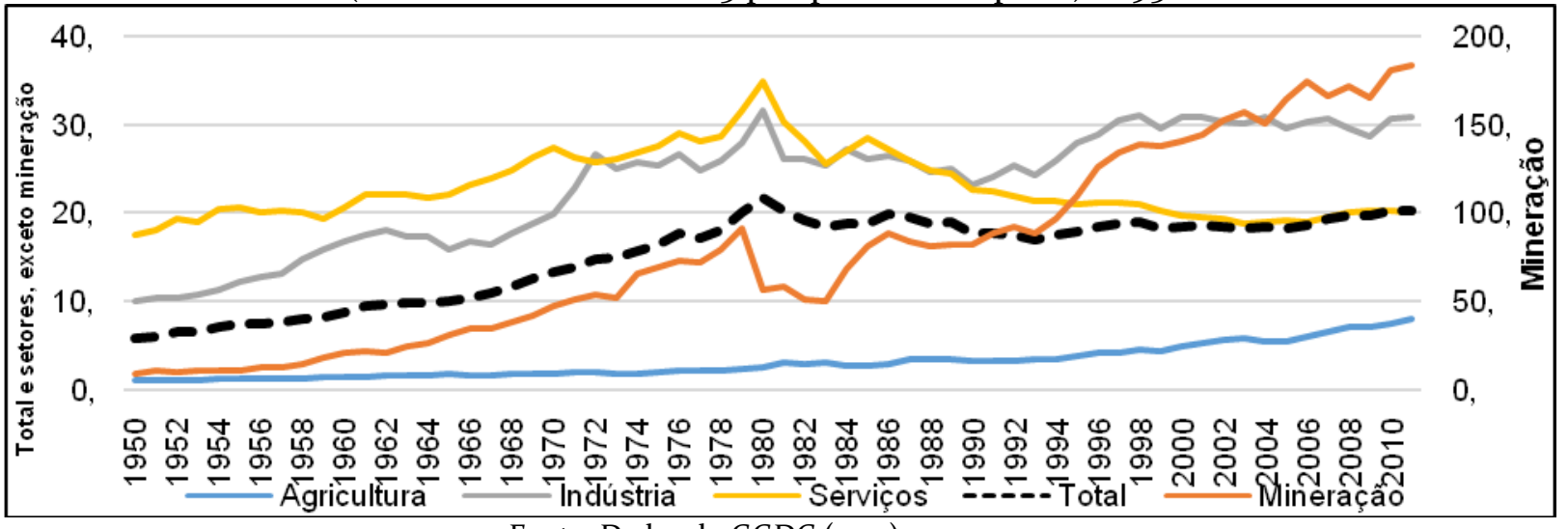

Fonte: Dados do GGDC (2017).

Segundo Dabla-norris et al. (2015), a alteração na produtividade dos países latino-americanos decorre da realocação setorial e da mudança estrutural em direção a setores de menor produtividade. No caso brasileiro (Gráfico 4), a produtividade total se eleva até o início da década de 1980, em correspondência ao aumento da produtividade da indústria e do setor de serviços.No início da série, o setor de serviços apresenta produtividade superior àquela observada na indústria. Posteriormente, a produtividade da indústria mantém o movimento de elevação, e a produtividade do setor de serviços 
declina. Assim, dois movimentos contribuem para a estagnação da produtividade brasileira nos anos recentes: a redução da participação da indústria no PIB e a redução da produtividade do setor de serviços. A recente elevação da produtividade da indústria é motivada, em grande parte, pelo aumento da produtividade da indústria extrativa (mineração).

Gráfico 5: Produtividade dos segmentos que compõem a indústria (milhões de US\$ de 2005) 1950 a 2011

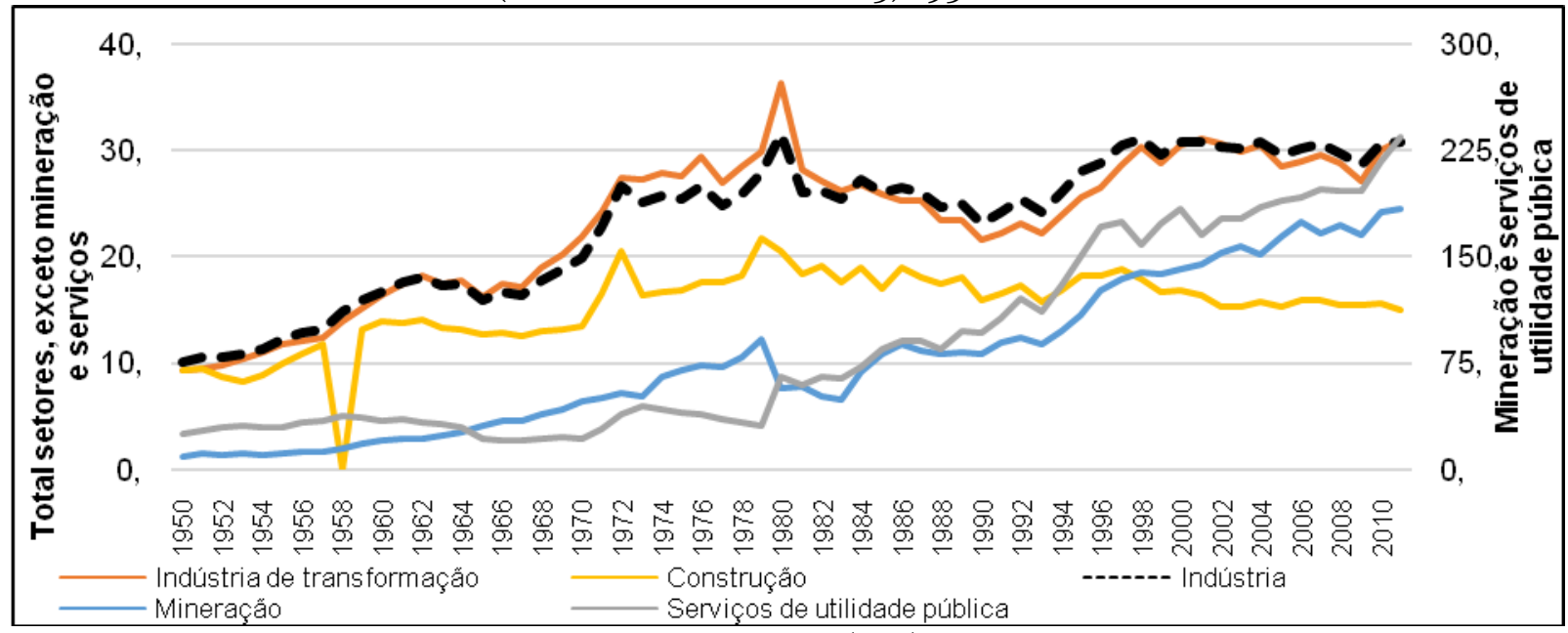

Fonte: Dados do GGDC (2017).

A produtividade dos segmentos que compõem a indústria é apresentada no Gráfico 5. O comportamento da indústria extrativa (mineração) e dos serviços industriais de utilidade pública vem representado no eixo secundário, pois ofusca os movimentos dos demais setores. Porém esses setores pouco condicionam a produtividade da indústria como um todo, o que decorre de suas baixas participações, tanto no valor adicionado quanto no emprego (Tabela 1). O segmento de maior expressividade na produtividade total da indústria é o de transformação, o que é explicado pelo peso que este tem para o setor industrial. Dada a elevada participação do segmento de transformação no setor industrial - muito superior à dos demais -, quando se aponta a redução da participação da indústria no PIB, essa afirmação refere-se, principalmente, à indústria de transformação. 
Tabela 1: Participação dos segmentos da indústria no total do emprego e valor adicionado do setor industrial - décadas de 1950, 1960, 1970 e 2000 (até 2011)

\begin{tabular}{|c|c|c|c|c|c|c|}
\hline \multirow[t]{4}{*}{ Segmento } & \multicolumn{6}{|c|}{ Participação na indústria (\%) } \\
\hline & \multicolumn{6}{|c|}{ Valor adicionado } \\
\hline & \multicolumn{6}{|c|}{ Décadas } \\
\hline & 1950 & 1960 & 1970 & 1980 & 1990 & 2000 \\
\hline Mineração & 2,7 & 4,0 & 4,1 & 5,8 & 7,2 & 8,3 \\
\hline Indústria de transformação & 65,7 & 68,4 & 66,9 & 62,0 & 59,2 & 60,5 \\
\hline Serviços de utilidade pública & 13,1 & 8,2 & 7,1 & 9,4 & 13,3 & 13,3 \\
\hline Construção & 18,4 & 19,4 & 21,9 & 22,8 & 20,3 & 17,9 \\
\hline \multirow[t]{2}{*}{ Indústria } & 100,0 & 100,0 & 100,0 & 100,0 & 100,0 & 100,0 \\
\hline & \multicolumn{6}{|c|}{ Emprego } \\
\hline Mineração & 2,8 & 2,3 & 1,6 & 2,2 & 1,8 & 1,5 \\
\hline Indústria de transformação & 70,1 & 66,6 & 61,9 & 62,0 & 63,6 & 61,8 \\
\hline Serviços de utilidade pública & 5,2 & 5,5 & 5,2 & 3,2 & 2,6 & 2,1 \\
\hline Construção & 22,0 & 25,6 & 31,3 & 32,7 & 31,9 & 34,6 \\
\hline Indústria & 100,0 & 100,0 & 100,0 & 100,0 & 100,0 & 100,0 \\
\hline
\end{tabular}

Fonte: Dados do GGDC (2017).

Nota: Dados numéricos arredondados.

A produtividade do setor de serviços, conforme se observa no Gráfico 6, cresce até 1980. A produtividade do setor de serviços é bastante condicionada pelo segmento de comércio, restaurantes e hotéis. Esse comportamento é reflexo da expressiva participação do segmento citado no setor, principalmente no que se refere ao emprego, que alcança índices superiores a 30\% em toda a série analisada. Por outro lado, a participação dos demais segmentos mostra-se bastante pulverizada, conforme se observa na Tabela 2.

No tocante ao valor adicionado, "comércio, restaurantes e hotéis","serviços financeiros, seguros, imobiliário e comercial" e "serviços governamentais" representam os segmentos de maior representatividade. Destes, o primeiro reduz sua participação ao longo dos anos, enquanto o último apresenta aumento. Referente ao emprego, o segmento "comércio, restaurantes e hotéis" é aquele de maior participação na série, com, aproximadamente, mais de dez pontos percentuais em relação ao segundo segmento, "serviços comunitários, sociais e pessoais". 
Gráfico 6: Produtividade dos segmentos que compõem o setor de serviços (milhões de US\$ de 2005) - 1950 a 2011

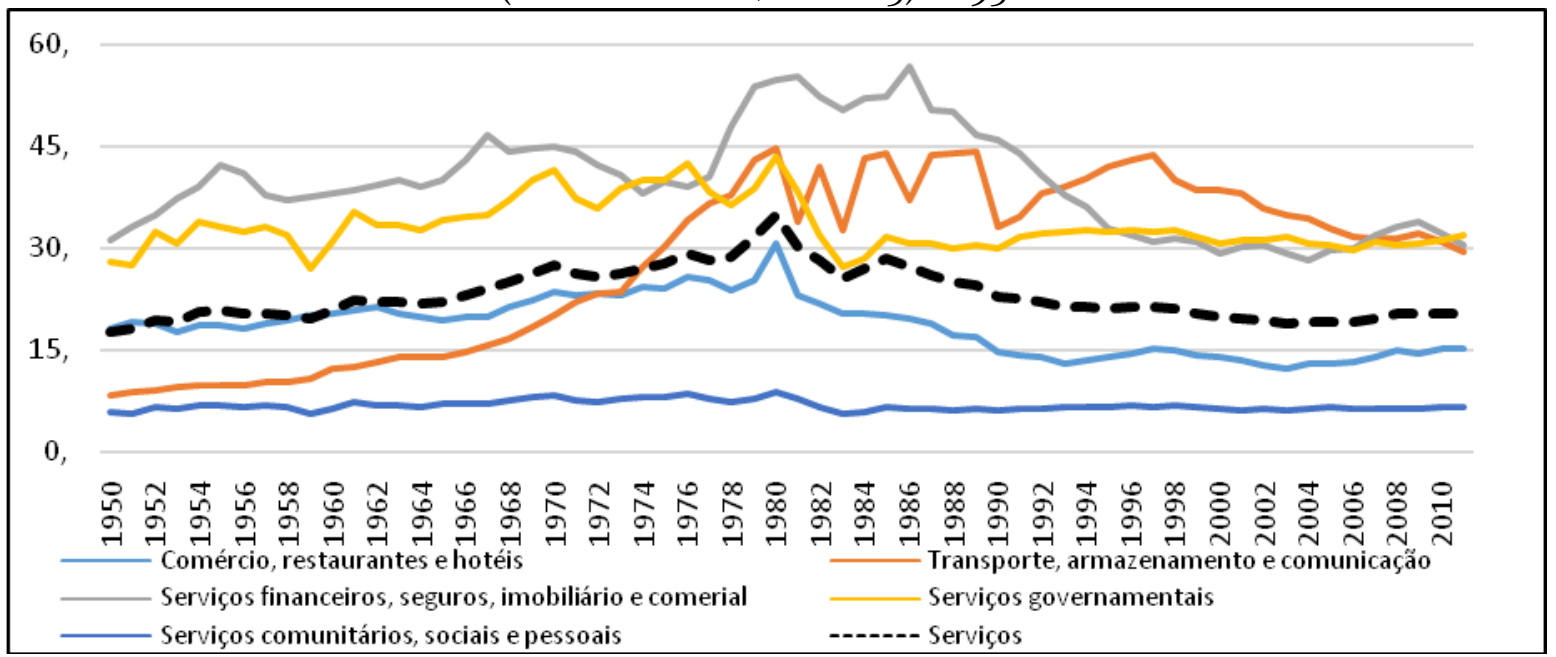

Fonte: Dados do GGDC (2017).

Tabela 2: Participação dos segmentos de serviços no total do emprego e valor adicionado do setor industrial - décadas de 1950, 1960, 1970 e 2000 (até 2011)

\begin{tabular}{|c|c|c|c|c|c|c|}
\hline Segmento & \multicolumn{6}{|c|}{ Participação no setor de serviços (\%) } \\
\hline & \multicolumn{6}{|c|}{ Valor adicionado } \\
\hline & \multicolumn{6}{|c|}{ Décadas } \\
\hline & 1950 & 1960 & 1970 & 1980 & 1990 & 2000 \\
\hline Comércio, restaurantes e hotéis & 32,6 & 28,9 & 26,5 & 22,5 & 22,0 & 23,5 \\
\hline Transporte, armazenamento e comunicação & 7,4 & 7,8 & 8,9 & 10,2 & 13,3 & 12,7 \\
\hline Serviços financeiros, seguros, imobiliário e comercial & 24,0 & 27,5 & 30,1 & 37,3 & 27,1 & 25,5 \\
\hline Serviços governamentais & 29,9 & 29,7 & 28,7 & 24,8 & 30,9 & 31,1 \\
\hline Serviços comunitários, sociais e pessoais & 6,1 & 6,1 & 5,9 & 5,1 & 6,7 & 7,2 \\
\hline \multirow[t]{2}{*}{ Serviços } & 100,0 & 100,0 & 100,0 & 100,0 & 100,0 & 100,0 \\
\hline & \multicolumn{6}{|c|}{ Emprego } \\
\hline Comércio, restaurantes e hotéis & 34,2 & 32,7 & 30,7 & 30,5 & 33,5 & 33,6 \\
\hline Transporte, armazenamento e comunicação & 15,0 & 12,5 & 8,2 & 6,9 & 7,3 & 7,6 \\
\hline Serviços financeiros, seguros, imobiliário e comercial & 12,6 & 15,2 & 19,4 & 19,7 & 16,2 & 16,3 \\
\hline Serviços governamentais & 19,0 & 19,8 & 20,8 & 21,4 & 20,7 & 19,9 \\
\hline Serviços comunitários, sociais e pessoais & 19,1 & 19,9 & 20,9 & 21,5 & 22,3 & 22,6 \\
\hline Serviços & 100,0 & 100,0 & 100,0 & 100,0 & 100,0 & 100,0 \\
\hline
\end{tabular}

Fonte: Dados do GGDC (2017).

Nota: Dados numéricos arredondados.

O setor de TICs ainda tem muito a se desenvolver na realidade brasileira, tanto em seus elementos mais fundamentais quanto no relacionamento que estabelece com os demais setores. Não obstante, seu impacto no crescimento do emprego é notório. Segundo a Pesquisa Anual de Serviços (PAS), em 2002 (dado mais antigo disponível), a participação do setor de Tecnologia da Informação (TI) no total de 
empregos do setor de serviços foi de 3,2\%. Em 2014, tal participação subiu para 4,5\%. O problema é que a participação no valor adicionado apresentou variação muito menor: de 6,6\% em 2002 para 6,9\% em 2014. Assim, pode-se concluir que a produtividade do setor de TI é superior àquela observada no setor de serviços, porém apresenta redução relativa de 2002 para 2014. Pode-se então questionar a capacidade do setor de promover a produtividade dos demais, uma vez que ele próprio apresenta dificuldade em sustentar sua produtividade ao longo do período (IBGE, 2017).

Diante do comportamento da produtividade brasileira, podemos apontar dois aspectos preponderantes: a redução da participação da indústria de transformação no PIB, que apresenta a segunda maior produtividade setorial recente e representatividade em termos de participação no emprego; e redução na produtividade do setor de serviços, juntamente com o aumento de sua participação no emprego total da economia nacional.

Nos períodos de avanço da indústria, a economia brasileira passou por um intenso movimento de êxodo rural. Os trabalhadores que deixaram a agricultura deslocaram-se para as cidades e inseriram-se principalmente na indústria. Atualmente, é possível observar que tanto os trabalhadores provenientes da agricultura quanto os do setor industrial se inserem no setor de serviços, pois, nesse último, não há necessidade de ampla qualificação como nos demais. A inserção maciça de trabalhadores no setor de serviços promove redução da produtividade, pois não se observa contrapartida igual no valor adicionado setorial.

Tratando-se da participação setorial do emprego, a agricultura detinha, na década de 1950, participação média de $62 \%$ no emprego brasileiro. Esse valor se reduz aos poucos, até alcançar $16 \%$ em 2010. Concomitante a esse movimento, o emprego do setor de serviços eleva-se em proporção semelhante. Na década de 1950 , a participação do setor de serviços na economia era de $21,5 \%$, ao passo que, em 2010, elevou-se para 61\%.

O Quadro 2, abaixo, descreve os efeitos Within-effect, realocação estática e realocação dinâmica, conforme modelo desenvolvido por Timmer, De Vries e De Vries (2014), com base em Fabricant (1942).

Quadro 2: Descrição de efeitos - decomposição canônica da produtividade

\begin{tabular}{|c|c|c|}
\hline Efeitos & Causa & Interpretação \\
\hline Within effect & Mudanças de produtividade setorial & $\begin{array}{c}\text { É positivo quando a produtividade setorial } \\
\text { aumenta. }\end{array}$ \\
\hline $\begin{array}{c}\text { Realocação } \\
\text { estática }\end{array}$ & $\begin{array}{c}\text { Deslocamento do emprego entre setores de } \\
\text { produtividade distinta }\end{array}$ & $\begin{array}{c}\text { É positivo quando o emprego se desloca } \\
\text { para setores de produtividade maior que a } \\
\text { média. }\end{array}$ \\
\hline $\begin{array}{c}\text { Realocação } \\
\text { dinâmica }\end{array}$ & $\begin{array}{c}\text { Deslocamento do emprego entre setores } \\
\text { com taxas de crescimento da produtividade } \\
\text { distintas }\end{array}$ & $\begin{array}{c}\text { É positivo quando o emprego se desloca } \\
\text { para setores onde a produtividade é crescente. }\end{array}$ \\
\hline
\end{tabular}

Fonte: Elaboração própria com base em Timmer, De Vries e De Vries (2014).

Levando-se em consideração tal descrição dos efeitos (Quadro 2) e as informações disponibilizadas na base de dados do GGDC, identificam-se os efeitos para três períodos distintos: 1960-1975 (boom econômico mundial), 1975-199o (mudança radical nos prospectos econômicos para as economias em desenvolvimento) e 1990-2010 (retomada do crescimento). Os resultados dos três efeitos para o Brasil são apresentados na Tabela 3: 
Tabela 3: Decomposição da produtividade do Brasil - 1960-1975, 1975 -1990 e 1990 -2010

\begin{tabular}{cccc}
\hline \multirow{2}{*}{ Período } & \multicolumn{3}{c}{ Efeito } \\
\cline { 2 - 4 } & Within-effect & Realocação estática & Realocação dinâmica \\
\hline $1960-1975$ & $1,9 \%$ & $2,0 \%$ & $0,3 \%$ \\
$1975-1990$ & $-0,5 \%$ & $1,4 \%$ & $-0,5 \%$ \\
$1990-2010$ & $0,7 \%$ & $0,4 \%$ & $-0,4 \%$ \\
\hline
\end{tabular}

Fonte: Elaboração e cálculo próprios com base em dados coletados em GGDC (2017).

Nota: Dados numéricos arredondados.

Sendo assim, para a realidade brasileira, no primeiro período, os três efeitos da decomposição foram positivos, sendo os efeitos de realocação estática e o "within-effect" maiores que o efeito de realocação dinâmico. Isso significa que houve aumento da produtividade dentro dos setores, aumento da participação no emprego por parte de setores mais produtivos (efeitos mais sobressalentes) e também expansão do emprego em setores nos quais a produtividade cresceu. De 1960 a 1975, a agricultura reduziu em $17 \%$ sua participação no emprego brasileiro. Em compensação, a participação da indústria aumentou em $5 \%$, e o setor de serviços, em $12 \%$. Os setores cuja participação cresceu apresentavam produtividade superior à da agricultura, muito embora, nesse período, a produtividade de todos os setores da economia tenha crescido.

No segundo período, apenas o efeito de realocação estática é positivo. Ou seja, houve aumento da participação no emprego de setores mais produtivos, porém a produtividade setorial declinou. $\mathrm{O}$ efeito de realocação dinâmica negativo aponta que os trabalhadores se moveram para setores que apresentaram retração de produtividade. Pode-se observar que, de 1975 a 1990, a agricultura seguiu perdendo participação no emprego nacional (-15\%); por sua vez, a indústria elevou sua participação em $1,4 \%$, e o setor de serviços mostrou-se o grande absorvedor de empregos, elevando sua participação em $14 \%$. O segundo efeito é positivo, pois a produtividade dos setores de indústria e de serviços - que absorvem emprego - foi maior do que a da agricultura. Contudo a produtividade decaiu de 1975 para 1990 na indústria $(-21,8 \%)$ e nos serviços $(-17,8 \%)$.

O "within-effect" e o efeito de realocação estática são positivos e mais baixos no terceiro período, o que significa aumento da produtividade setorial e deslocamento de emprego para setores de produtividade superior à média. Todavia o efeito de realocação dinâmica é negativo, o que implica que o emprego se expandiu em setores em que a produtividade decaiu. A produtividade brasileira aumentou 14,5\% nos 20 anos compreendidos entre 1990 e 2010 . Apenas o setor de serviços ganhou participação no emprego $(12,2 \%)$. A indústria de transformação reduziu aproximadamente $3 \%$ e a agricultura contraiu $10 \%$. Desses setores, a produtividade elevou-se na agricultura e na indústria de transformação, reduzindo-se justamente no setor de serviços, no qual a participação no emprego se elevou.

Nesse contexto, conclui-se que, para o caso brasileiro, a evolução da produtividade é coerente com a mudança estrutural observada. No primeiro período, tanto o crescimento da indústria quanto do setor de serviços no emprego traz consigo aumento de produtividade, uma vez que esses setores se mostram mais produtivos que a agricultura. Pode-se afirmar que, a partir do segundo período, o comportamento da produtividade é coerente com o aumento do emprego em setores onde a produtividade decresce, principalmente no setor de serviços, o que evidencia que a terceirização associada à maior complexidade econômica, conforme apresentado na seção anterior, não ocorre no caso brasileiro.

Em realidade, nesse caso, o crescimento da participação do setor de serviços no emprego relacionase mais com um aumento do emprego nos segmentos de serviços financeiros, seguros, imobiliário e comercial e serviços comunitários, sociais e pessoais, do que da terceirização nos moldes explanados. Segundo Arbache (2015, p. 277), o crescimento do setor de serviços não decorreu do aumento da renda média, de mudança da composição da demanda, do crescimento industrial "ou outros fatores que poderiam ter desencadeado o desenvolvimento do setor de serviços, como acontecera nos países 
industrializados". Ou seja, não ocorreu no Brasil a terceirização inteligente fomentada por um processo completo de industrialização.

Ainda como descreve Arbache (2015, p. 277), corroborando os achados aqui apresentados, a participação do setor de serviços cresce mais em razão do crescimento vegetativo e da perda de dinamismo de outros setores, diferentemente do que ocorre no próprio setor de serviços. O crescimento da população urbana e a transformação demográfica podem ter contribuído para isso, assim como as características do próprio setor de serviços - baixo custo à entrada, baixa necessidade de capital humano e tecnológico. O setor de serviços, portanto, foi "a melhor, senão a única oportunidade de renda e emprego para boa parte do contingente de pessoas que chegava ao mercado de trabalho".

\section{Considerações finais}

Atualmente, o cenário mundial acerca da produtividade é de estagnação. Por vezes, atribui-se esse comportamento aos processos de desindustrialização, o que promove redução da indústria - setor de alta produtividade - em benefício do aumento da participação do setor de serviços - setor de produtividade inferior - nas economias. Porém verifica-se que esse processo é dúbio, uma vez que ele depende da conformação da estrutura produtiva previamente ao seu acontecimento.

Quando se observa a emergência de um setor de serviços tradicional, que absorve grande quantidade de mão de obra e é normalmente pouco receptivo à inovação, o resultado assemelha-se com o descrito na literatura econômica como doença dos custos. Em contrapartida, no caso do crescimento de um setor de serviços dinâmico, inter-relacionado com a indústria e receptivo à inovação, o resultado expressa-se por meio de ganhos de produtividade agregada.

Nas economias avançadas, a terceirização de atividades da indústria para o setor de serviços decorre do aprofundamento do paradigma tecnológico fundamentado nas TICs. Este se inicia após a consolidação de um setor industrial robusto. Nas economias em desenvolvimento, observa-se que o processo de desindustrialização se inicia antes de se alcançar a consolidação do setor industrial, o que dá origem a um setor de serviços pouco integrado aos demais setores produtivos.

Nesse contexto, conclui-se que, para o caso brasileiro, a evolução da produtividade é coerente com a mudança estrutural observada. No primeiro período (1960-1975), tanto o crescimento da indústria quanto do setor de serviços no emprego traz consigo aumento de produtividade, visto que esses setores se mostram mais produtivos que a agricultura. Pode-se afirmar que, a partir do segundo período (1975-1990 e 1990-2010), o comportamento da produtividade é coerente com o aumento do emprego em setores onde a produtividade decresce, principalmente no setor de serviços, o que evidencia que a terceirização capaz de aumentar a complexidade econômica não ocorre no caso brasileiro.

Aqui, o crescimento da participação do setor de serviços no emprego relaciona-se mais ao aumento do emprego nos segmentos de serviços financeiros, seguros, imobiliário e comercial, e serviços comunitários, sociais e pessoais do que com a terceirização nos moldes explanados. O setor de serviços cresceu mais devido à ausência de dinamismo nos outros setores do que por conta do seu próprio dinamismo. Suas características de baixo custo à entrada o transformaram na opção mais viável de emprego para aqueles que adentravam o mercado de trabalho. Logo, o setor de serviços possibilitou absorção de emprego, ratificou a existência de um processo de desindustrialização e promoveu estagnação da produtividade na economia nacional.

\section{Referências}

AMBROZIO, Antonio Marcos Hoelz Pinto; MELO, Luciane Paiva D’Ávila. A nova imagem do setor de serviços. Textos Para Discussão - BNDES, Rio de Janeiro, v. 1, n. 119, p.1-36, jan. 2017. 
ANTONELLI, C. Localized technological change, new information technology and the knowledge-based economy: the European evidence. Journal of Evolutionary Economics, v. 8, n. 2, p. 177-198, jul. 1998.

ARBACHE, J. Produtividade no setor de serviços. In: DE NEGRI, F.; CAVALCANTE, L. R. (Orgs.). Produtividade no Brasil: desempenho e determinantes. Brasília: , 2015. v. 2, p. 277-300.

BAUMOL, W. J. (1967), 'Macroeconomics of unbalanced growth: the anatomy of urban crisis', The American Economic Review 57(3), 415-426.

BAUMOL, W. J.; BLACKMAN, S. A. B.; Wolff, E. N. (1985), 'Unbalanced growth revisited: asymptotic stagnancy and new evidence', The American Economic Review 75(4), 806-817.

BUSSO, M., MADRIGAL, L.; PAGES, C. (2013), 'Productivity and research missallocation in latin american', The B.E. Journal of Macroeconomics 13(1), 903-932.

CASTELLACCI, F. Technological paradigms, regimes and trajectories: Manufacturing and service industries in a new taxonomy of sectoral patterns of innovation. Research Policy, Oslo, v. 1, n. 37, p. 978994, 15 maio 2008. Disponível em: <https://myweb.rollins.edu/tlairson/pek/techpara2.pdf>. Acesso em: 12 set. 2017.

DABLA-NORRIS, Era et al. The New Normal: A Sector-Level Perspective on Productivity Trends in Advanced Economies. Washington: FMI, 2015. 38 p.

DI CAGNO, D.; MELICIANI, V. Do inter-sectoral flows of services matter for productivity growth? An input/output analysis of OECD countries. Economics of Innovation and New Technology, v. 14, n. 3: 149171, 2005.

FABRICANT, S. Employment in Manufacturing, 1899-1939. NBER, New York, 1942.

FIXLER, D.; SIEGAL, D. Outsourcing and productivity growth in services. Structural Change and Economic Dynamics, n. 10, p. 177-194, 1999.

FREEMAN, C., LOUÇÃ, F. As Time Goes by: From the Industrial Revolutions to the Information Revolution. Oxford: Oxford University Press, 2001.

GUERRIERI, P., MELICIANI, V. Technology and international competitiveness: the interdependence between manufacturing and producer services. Structural Change and Economic Dynamics, n. 16, p. 489502,2005 .

JACINTO, P. de A.; RIBEIRO, E. P. Crescimento da Produtividade no setor de serviços e da indústria no Brasil: dinâmica e heterogeneidade. Economia Aplicada, São Paulo, v. 19, n. 3, 2015, p. 401-427.

LAZZARI, Martinho Roberto. Três ensaios sobre mudança estrutural e desempenho econômico. 2019. Tese (Doutorado) - Curso de Economia, Faculdade de Ciências Econômicas, UFRGS, Porto Alegre, 2019. 
MARCONI, Nelson; ARAGÃO, Roberto Barbosa de Andrade. Demand and supply factors on the explanation of structural change. Porto: FMM, 2016.

MELO, H. P.; ROCHA, F.; FERRAZ, G.; DI SABBATO, A.; DWECK, R. (1998), 'O setor serviços no Brasil: uma visão global - 1985/95'.

MCMILLAN, M.; RODRIK, D. Globalization, Structural Change, and Economic Growth. In: BACHETTA, M.;. JANSEN, M. (Eds.).Making Globalization Socially Sustainable, International Labor Organization and World Trade Organization, Geneva, 2011.

OLIVEIRA, C. C. (2011), 'Os serviços importam: análise comparativa da evolução setorial da produtividade do trabalho no Brasil, nos EUA e na EU-15 (1980-2007): uma aplicação do modelo Shift share', XXXIX Encontro Nacional de Economia, Foz do Iguaçu, Paraná.

PEREIRA, M. Z.; BASTOS, S. Q. A.; PEROBELLI, F. S. (2013), 'Análise sistêmica do setor de serviços no Brasil para o ano de 2005', Pesquisa e Planejamento Econômico 43(1), 161-201.

RODRIK, DANI, “Unconditional Convergence in Manufacturing," Quarterly Journal of Economics, 128 (1), February 2013, 165-204.

RODRIK, Dani. 'O imperativo manufatureiro', Valor econômico, 2011.Disponível em: <https://www.valor.com.br/colunistas/Dani\%2oRodrik>. Acesso em: 29 ma. 2019.

RODRIK, Dani. 'Are services the new manufactures?', Valor econômico, 2014. Disponível em: <https://www.valor.com.br/colunistas/Dani\%2oRodrik>. Acesso em: 29 ma. 2019.

SILVA, A. M. Dinâmica da produtividade do setor de serviços no Brasil: uma abordagem microeconômica. In: DE NEGRI, J. A.;KUBOTA, L. C. (Eds.). Estrutura e Dinâmica do Setor de Serviços no Brasil. Brasília: IPEA, 2006.

SQUEFF, G. C.; DE NEGRI, F. Produtividade do trabalho e mudança estrutural no Brasil nos anos 2000. In: DE NEGRI, F.; CAVALCANTE, L. R.; (Orgs.). Produtividade no Brasil: desempenho e determinantes. Brasília: ABDI: IPEA, 2014, v. 1, p. 249-280.

THE CONFERENCE BOARD (Estados Unidos). Productivity data. 2015. Disponível em: . Acesso em: o6 ago. 2016.

THE CONFERENCE BOARD. Productivity Brief 2015: Global Productivity Growth Stuck in the Slow Lane with No Signs of Recovery in Sight. Nova York, 2015. 26 p. Disponível em: <https://www.conferenceboard.org/retrievefile.cfm?filename=the-conference-board-2015-productivity-brief.pdf\&type=subsite $>$. Acesso em: 12 set. 2017.

THE CONFERENCE BOARD. Productivity Brief 2019: Nova York, 2019. 27 p. Disponível em: $<$ https://www.conferenceboard.org/retrievefile.cfm?filename=TED_ProductivityBrief_20191.pdf\&type=s ubsite >. Acesso em: 31 mai. 2019.

TIMMER, M. P.; DE VRIES, G.; DE VRIES; K. Patterns of Structural Change in Developing Countries. Groningen: Groningen Growth and Development Centre, 2014. 31 p. 
TIMMER, Marcel P.; SZIRMAI, Adam, 200o. "Productivity growth in Asian manufacturing: the structural bonus hypothesis examined," Structural Change and Economic Dynamics, Elsevier, vol. 11(4), pages 371392, December.

TOREZANI, Tomás Amaral. Evolução da produtividade brasileira: mudança estrutural e dinâmica tecnológica em uma abordagem multissetorial. 2019. Tese (Doutorado) - Curso de Economia, Faculdade de Ciências Econômicas, UFRGS, Porto Alegre, 2018.

WINDRUM, P., TOMLINSON, M. Knowledge-intensive services and international competitiveness: a four country comparison. Technology Analysis and Strategic Management, v. 11, n. 3, p. 391-408, 1999.

Recebido em 30.11.18

Aprovado em 19.06.19 